\title{
Reduced vaginal elasticity, reduced lubrication, and deep and superficial dyspareunia in irradiated gynecological cancer survivors
}

\author{
Karin Stinesen Kollberg, Ann-Charlotte Waldenstrom, Karin Bergmark, Gail Dunberger, \\ Anna Rossander, Ulrica Wilderang, Elisabeth Åvall Lundqvist and Gunnar Steineck
}

\section{Linköping University Post Print}

\section{Tweet}

N.B.: When citing this work, cite the original article.

Original Publication:

Karin Stinesen Kollberg, Ann-Charlotte Waldenstrom, Karin Bergmark, Gail Dunberger, Anna Rossander, Ulrica Wilderang, Elisabeth Åvall Lundqvist and Gunnar Steineck, Reduced vaginal elasticity, reduced lubrication, and deep and superficial dyspareunia in irradiated gynecological cancer survivors, 2015, Acta Oncologica, (54), 5, 772-779.

http://dx.doi.org/10.3109/0284186X.2014.1001036

Copyright: Informa Healthcare http://informahealthcare.com/

Postprint available at: Linköping University Electronic Press http://urn.kb.se/resolve?urn=urn:nbn:se:liu:diva-118860 


\section{Original report:}

Reduced vaginal elasticity, reduced lubrication, and deep and superficial dyspareunia in irradiated gynecological cancer survivors

Authors:

Karin Stinesen Kollberg, Ph.D. ${ }^{1}$, Ann-Charlotte Waldenström, M.D., Ph.D. ${ }^{1}$, Karin Bergmark, M.D., Ph.D. ${ }^{1,2}$, Gail Dunberger, R.N., Ph.D. ${ }^{2,3}$, Anna Rossander, M.D. ${ }^{4}$, Ulrica Wilderäng, Ph.D. ${ }^{1}$, Elisabeth Åvall-Lundqvist, M.D., Ph.D. ${ }^{2,5}$, and Gunnar Steineck, M.D., Ph. D ${ }^{1,2}$.

\section{Affiliations}

${ }^{1}$ Division of Clinical Cancer Epidemiology, Department of Oncology, Institute of Clinical Sciences, The Sahlgrenska Academy, University of Gothenburg, Sweden.

${ }^{2}$ Division of Clinical Cancer Epidemiology, Department of Oncology-Pathology, Karolinska Institute, Stockholm, Sweden.

${ }^{3}$ Ersta Sköndal University College, Stockholm, Sweden.

${ }^{4}$ Department of Urology, Hallands Hospital Kungsbacka, Kungsbacka, Sweden

${ }^{5}$ Department of Oncology and Department of Clinical and Experimental Medicine, Linköping University, Sweden

\section{$\underline{\text { Research support: }}$}

This study was funded by grants from the Swedish Cancer Society, the Cancer Research Funds of Radiumhemmet, the King Gustav V Jubilee Clinic Cancer Foundation, Gothenburg, and the Swedish State under the ALF agreement, Stockholm and Gothenburg.

\section{Acknowledgements:}

The authors gratefully acknowledge the participants in the study.

\section{Disclaimer:}

No conflicts of interest declared. The authors alone are responsible for the content and writing of the manuscript.

Corresponding author:

Karin Stinesen Kollberg, Ph. D.

Division of Clinical Cancer Epidemiology

Department of Oncology, Sahlgrenska Academy at University of Gothenburg

41345 Gothenburg, Sweden

E-mail: karin.stinesen@oc.gu.se

Telephone: +46768521972 Fax: +4631209250

Running head:

Vaginal elasticity, lubrication, and dyspareunia in irradiated gynecological cancer survivors 


\begin{abstract}
Purpose

The purpose of this study was to examine whether or not vaginal elasticity or lack of lubrication is associated with deep or superficial dyspareunia. We investigated gynecological cancer survivors treated with radiation therapy.
\end{abstract}

\title{
Methods
}

In a population-based study with 616 women answering a questionnaire (participation rate $78 \%$ ) and who were treated with radiotherapy for gynecological cancer, we analyzed information from 243 women (39\%) who reported that they had had intercourse during the previous six months. Analyses included log-binomial regression (relative risks) and multiple imputations by chained equations in combination with Bayesian Model Averaging, yielding a posterior probability value. Age range of this cancer recurrent-free group of women was 29 through 80 .

\section{Results}

Dyspareunia affected 164 out of 243 of the women (67\%). One hundred thirty-four women (55\%) reported superficial pain, 97 women (40\%) reported deep pain, and 87 women (36\%) reported both types of dyspareunia. The relative risk (RR) of deep dyspareunia was 1.87 (CI 1.41-2.49) with impaired vaginal elasticity compared to normal vaginal elasticity. Age and lower abdominal swelling were separate risk factors for deep dyspareunia. However, effects remain after adjusting for these factors.

\section{Conclusion}

The relative risk of deep dyspareunia was almost twice as high with impaired vaginal elasticity compared to normal vaginal elasticity. If we wish to treat or even prevent deep dyspareunia in women with gynecological cancer, we may use our knowledge of the pathophysiology of deep dyspareunia and increasingly provide dilators together with instructions on how to use them for stretching exercises in order to retain vaginal elasticity. Results highlight the need for studies with more precise questions distinguishing superficial from deep dyspareunia so that in the future we may be able to primarily try to avoid reduced vaginal elasticity and secondarily reduce the symptoms. 
Title: Reduced vaginal elasticity, reduced lubrication, and deep and superficial dyspareunia in irradiated gynecological cancer survivors

\section{INTRODUCTION}

It is challenging to prevent or treat that which is not understood. Women treated with radiation therapy for a gynecological cancer report a variety of physical, psychological, and social problems documented to affect quality of life such as fecal incontinence [1], lower limb lymphedema [2], pain and fatigue [3], emotional distress [4], and problems related to sexual health [5-8]. Studies have focused on women's experiences with impaired sexual health after having undergone treatment for gynecological cancer [9-12]. Evidence in the literature demonstrates dyspareunia (pain with intercourse) among these women to be a common, debilitating problem as one in five women report painful symptoms with intercourse [7]. These women suffer first from their long-term dysfunction [13] and secondly, as their problems are rarely addressed by health care staff [14]. In order to move this field forward, we need to better understand the underlying pathophysiology of dyspareunia so that we in the future may treat or even prevent it. The purpose of this study was to examine whether or not vaginal elasticity or lack of lubrication is associated with deep or superficial dyspareunia. We have used a validated questionnaire based on clinometrically atomized patient-reported outcomes [15] to survey factors associated with dyspareunia in a cohort of irradiated gynecological cancer survivors and analyzed these data.

\section{METHODS}

\section{Participants}

The Swedish registry system provides nearly everyone living in Sweden with a personal identity number [16]. Through this system, we identified 1800 women who had received radiation treatment in the pelvic region for gynecological malignancies between March 1991 and December 2003 at Radiumhemmet Karolinska University Hospital, Stockholm, or between December 1994 and December 2003 at Sahlgrenska University Hospital, Gothenburg. Inclusion criteria were no evidence of recurrence, age $<80$ years, and able to read and understand Swedish. The study was approved by respective regional ethics committee and the women gave both oral and written consent to participate.

Study preparation and data collection 
We applied clinical epidemiological methods to systematically recognize the possible causes of bias in each step of the research process [17]. The questionnaire used in the study was developed by our division according to a well established clinometric method focused on atomizing symptoms [18-20]. Detailed information about the study-specific questionnaire and the specific treatments for this group was described by Lind et al in a previous publication [21]. The questionnaire for this study was based on interviews with gynecological cancer survivors and validated face-to-face using women within the study population, ensuring that the questions were understood the way they were intended. The questionnaire was also tested for participation rate and for rate of missing values. The questionnaire included 351 questions and was divided into different sections covering demographic data, information concerning disease and treatment, quality of life, physical symptoms of the pelvic region, and social functioning. Of these questions, 59 dealt with sexuality. Information regarding cancer diagnoses, stage of disease, and treatment techniques regarding surgery, radiation treatment, and chemotherapy was collected from medical records.

\section{Measurements}

The questions were phrased to represent the previous six months regardless of when the treatment took place and thus able to detect long-term effects. Dyspareunia was assessed by asking "During the previous six months, have you had pain in the vaginal membranes or vaginal introitus (superficial dyspareunia) during intercourse?" and "During the previous six months, have you felt pain in the vagina and in the pelvis (deep dyspareunia) with intercourse?" with anchors "No, not at all", "Yes, a little", "Yes, quite a bit", and "Yes, very much". Questions regarding dyspareunia were dichotomized into "dyspareunia" and "no dyspareunia". Questions related to potentially associated factors were dichotomized to "no/little dysfunction" or "moderate/high dysfunction" during the previous six months. Here, only the answer "no" was classified as not having dyspareunia. For both these questions there was also an alternative to respond "Not relevant, I have not had intercourse during the previous six months".

Questions regarding potentially associated factors were: "During the previous six months, how has your vaginal elasticity been?" with anchors "None at all", "Poor", "Moderate", and "Good". In the analyses, we classified "None at all" and "Poor" as reduced vaginal elasticity and "Moderate" and "Good" as normal elasticity. We also analyzed the question "During the previous six months, has your vagina become moist during sexual arousal?" with anchors 
"Not relevant, I have not been sexually aroused during the previous six months", "No, not at all", "Yes, a little", "Yes, quite a bit", and "Yes, very much". In the analyses, the responses "No, not at all" and "Yes, a little" were classified as having reduced lubrication. Finally, "In the previous six months, during sexual arousal, have you noticed if labia, clitoris or outer parts of the vagina have felt swollen and engorged?" with anchors "Not relevant, I have not been sexually aroused during the previous six months", "No, never", "Yes, less than half the time when I have been sexually aroused", "Yes, more than half the times", and "Yes, every time". In the analyses, we classified "No never" and "Yes, less than half the time when I have been sexually aroused" as reporting reduced genital engorgement.

\section{Statistical analysis}

Statistical analyses include descriptive statistics of the women's sociodemographic and treatment related characteristics (Table 1). We calculated the percentage of respondents in each category of the potentially associated factors with outcome and formed ratios of these percentages (relative risks) as a measure of the strength of the association between the independent variable and the outcome with $95 \%$ corresponding confidence intervals (CI) (Table 2). We analyzed the association between potentially associated factors (elasticity, lubrication, engorgement) and the outcomes of superficial and deep dyspareunia respectively, using multiple imputations by chained equations (MICE) in combination with Bayesian Model Averaging yielding a percentage, the Posterior Probability Value (PPV). PPV values show levels of existing statistically significant associations: $>99 \%$ as very strong, 95-99\% as strong, $75-95 \%$ as positive, and 50-75\% as a weak association. We used multiple imputations for the following variables: marital status, parity, age, smoking, genital engorgement, vaginal lubrication, and vaginal elasticity. Calculations were performed using the SAS statistical software version 9.2 (SAS Institute Inc., Cary, N.C., U.S.A.).

\section{RESULTS}

\section{Participants}

Data were collected from 616 gynecological cancer survivors (78\% participation rate) treated with external radiation therapy. Out of these, 243 women (39\%) reported having had sexual intercourse during the previous six months (Figure 1). Median time between end of radiation treatment and follow-up time was seven years for women who had had intercourse during the previous six months and eight years for those not engaging in intercourse. Time range from treatment to data collection was 3 to 15 years. Most survivors (90\%) had been treated with 
surgery plus radiation treatment and the remaining had received radiation treatment only. Eighty-one percent of the women also had undergone brachytherapy. Chemotherapy treatment had been added for 33 percent of the women. The two largest groups of diagnoses were endometrial and cervical cancer (Table 1).

Deep and superficial dyspareunia

In the group of sexually active women $(n=243), 55$ percent reported superficial dyspareunia, 40 percent reported deep dyspareunia, 36 percent reported both superficial and deep dyspareunia, and 34 percent reported no dyspareunia (Table 1, Figure 2). Sixty-one percent of the women reported not having had intercourse during the previous six months. Seven percent declined to answer the question on dyspareunia (Table 1). Of all women who reported they had had sexual intercourse, the response rates ranged from 93 to 95 percent for the questions regarding dyspareunia, vaginal elasticity, lubrication, and genital engorgement. Dyspareunia affected 164 out of 243 women (67\%). Of those who reported having had intercourse during the previous six months, 145 women $(60 \%)$ reported intercourse up to twice per month, and 98 women $(40 \%)$ reported intercourse more often (Data not shown in table). The relative risk of deep dyspareunia was 1.87 (1.41-2.49) with impaired patient-reported elasticity (none or poor) compared to those who reported moderate or good elasticity and the relative risk of superficial dyspareunia was 1.58 (1.29-1.93) with impaired elasticity

(Table 2). Bayesian Model Averaging yielded lubrication (PPV100\%) and swollen lower abdomen (PPV 87\%) as variables associated with superficial dyspareunia and the variable found to be associated with deep dyspareunia was vaginal elasticity with a posterior probability of 100\%) (Data not shown). Age was a separate risk factor for deep dyspareunia and both of these effects remain after adjusting for each of them separately and together (Table 2). We found no statistically significant correlation between grade of genital engorgement with arousal and dyspareunia. There was no statistically significant correlation between impaired vaginal elasticity and superficial dyspareunia after adjusting for impaired lubrication (Table 2). Nearly 50 percent of the respondents answered "not relevant" when possible. When no such response alternative was available, the rate of missing answers was higher. At the most, it was 20 percent.

\section{DISCUSSION}

The relative risk of deep dyspareunia was almost twice as high among women who reported impaired elasticity (none or poor) compared to those who reported moderate or good 
elasticity. To prevent or relieve deep dyspareunia, we need to find means to increase vaginal elasticity. To prevent or relieve superficial dyspareunia, we need to find means to increase lubrication and reduce atrophy with friction being the major problem in this population of gynecological cancer survivors.

It is difficult to find comparable results in the literature since to our knowledge only one prior study has distinguished superficial dyspareunia from deep dyspareunia. In the study by Bergmark and colleagues, comprising 256 women with early stages of cervical cancer (stages IB or IIA), vaginal shortness was found to be associated with deep as well as superficial dyspareunia whereas reduced vaginal elasticity and lubrication were associated with superficial dyspareunia only [7]. Several factors may explain the differences in these results. First, women's demographic characteristics differed in the two studies. In comparison with the survivors in the study presented here who were diagnosed with different types of gynecological cancer, Bergmark's data set comprised women with cervical cancer only and most of them had had surgery for cervical cancer which in itself shortens the vagina by two to three centimeters, and thus possibly, may give rise to a sense of reduced elasticity. Moreover, 158 women in Bergmark's study (61\%) were treated with radiation treatment (the rest were treated with surgery only) whereas in this study, all 616 women had undergone radiation treatment. In addition, even though Bergmark's is the only identified study that has taken both superficial and deep dyspareunia into account, we are unable to exclude the possibility of misclassification as the questions in the two studies were not identical. As such, the results may not be entirely comparable.

Without fully comparable results, we reasoned that one may consider reduced vaginal length as the extreme form of reduced elasticity lengthwise, hence, with caution we may use reduced vaginal length as a proximal variable for reduced elasticity. To that end, we found a number of publications linking shortened vagina with unspecified dyspareunia [8, 10, 22]. In one longitudinal study, Jensen and colleagues found persistent sexual dysfunction up to two years after radiation treatment $(\mathrm{n}=118)$ [8]. There was a high prevalence of dyspareunia in this group of women (50-60\%), and significant differences between women treated with radiation treatment and the control group ( $p 0.024$ to $<0.001$ ). Forty-eight percent of the women reported a smaller vaginal dimension $(p=0.002)$ at 12 months after end of radiation treatment in comparison with levels before the cancer diagnosis, 7 out of $24(29 \%)$ reported a bothersome size of the vagina at 12 months, and 4 out of $24(17 \%)$ reported quite a bit to very 
much dyspareunia [8]. However, this study did not distinguish deep dyspareunia from superficial dyspareunia. Also, the follow-up time since treatment was different from our study as Jensen and colleagues followed their survivors from termination of radiation treatment until two years later whereas the data in our study were collected at least three years or more after end of radiation treatment. Nonetheless, even though the follow-up time was different from our study, their results along with a persistent pattern of low or no sexual interest offer insight to how tightly intertwined the symptoms are in addition to the profound role they play in recovering one's sexual health after radiation treatment. We identified age, reduced lubrication, and lower abdominal swelling as potential confounders of superficial and deep dyspareunia, respectively and have thus adjusted for these in the analyses [23, 24].

The proportion of women who reported not having had intercourse in the previous six months deserves mentioning. We do not know the reason for abstaining from intercourse. For those who have a partner, one possibility may be that they abstain as a result of previous experience with pain associated with this type of sexual activity. Fear of cancer in general [25], and in particular of gynecological cancer as a threat against the most inner core of what commonly embodies a sense of being a woman, may contribute to the women avoiding intercourse altogether. Layered on this is the preconceived societal notion that older women "should not" be sexually active, thus labeling the desire for intercourse something to be ashamed of [26], a stigma certainly not conducive to actively seeking support and treatment for this problem. As a result, it would be plausible if women may simply "give up trying" and opt for avoiding intercourse. Hence, we speculate that the rate of intercourse reported by the participants could reflect a population experiencing a pronounced sexual dysfunction. Indeed, the high response rate of these intimate, very private questions in this study clearly reflects that these are concerns that women regardless of age do have.

Our study is strengthened by a fairly large number of participants and a reasonably high participation rate. Using a national population-based registry, we believe that the risk for selection-induced errors was minimized. Moreover, the use of the national registry gave us full control of the denominator when calculating the participation rate. Since the participants responded to our carefully designed and constructed questionnaire in private, we may likely have reduced the risk for measurement errors and as well as any interview-induced bias. Also, using detailed face-to-face validated questions concerning these symptoms shows that women are able to distinguish between superficial and deep dyspareunia. Nonetheless, there are 
limitations to our study. First, we cannot exclude the possibility that the results would have differed if all eligible women would have responded to the questionnaire. Second, we do not have information on important reasons for superficial dyspareunia including genital atrophy or estrogen treatment. Third, approximately half of the women reported that they had not had intercourse during the previous six months. Thus, they were included in the descriptive portion of this report however not part of the analytic part. Regardless of reason for refraining from intercourse, however, this would likely deviate the prevalence ratio towards 1.0. Fourth, this study lacks information on the frequency of dyspareunia among the women experiencing this symptom. In order to simplify for the women, we chose not to ask them the percentage of painful episodes and instead chose to ask them about the intensity (severity) of their dyspareunia. Irrespective of treatment modality, we believe that the effect of deep dyspareunia is largely mediated by vaginal elasticity. That is, aspects of treatment are not possible confounders. They are not confounders but rather associated with the independent factor of study (vaginal elasticity). Women who had not had sexual intercourse during the previous six months answered "Not relevant, I have not had sexual intercourse during the previous six months" on questions concerning reduced vaginal elasticity and deep dyspareunia. As such, we have no information from them: our finding primarily concerns women who had had sexual intercourse. For some questions, for example concerning vaginal elasticity, we overlooked to provide an anchor for women who were not sexually active. As a result, there is a higher rate of missing answers for these questions. Finally, we do not have sufficient information to evaluate hormonal status of the women in this group, a factor which well may affect a woman's vaginal atrophy and lubrication capacity [27] and, thus, experience of superficial dyspareunia.

We found that deep dyspareunia was primarily associated with reduced vaginal elasticity and that superficial dyspareunia was primarily associated with reduced lubrication. One way to move this field forward is to learn how to prevent and treat reduced vaginal elasticity and reduced lubrication. If we wish to treat or even prevent deep dyspareunia in women with gynecological cancer, we may use our knowledge of the pathophysiology of deep dyspareunia and increasingly provide dilators together with instructions on how to use them for stretching exercises in order to retain vaginal elasticity. To prevent reduced lubrication for superficial dyspareunia, we may consider finding means to increase lubrication by better understanding the underlying causes of reduced lubrication. In our aim to treat reduced lubrication, however, we may consider providing information about suitable topical hormonal creams, which help 
to maintain the vaginal mucous membrane. In research, our results highlight the need for randomized controlled studies that aim to minimize the physical and psychological morbidity as a result of radiation treatment for gynecological cancer. One such intervention was carried out in Australia in which women were provided with dilators and the follow-up thereafter was carried out through a combination of nursing consultants and telephone peer support [28] and a similar study conducted in the United States [29]. Results from these studies are pending but may provide needed new insight to these problems affecting thousands of women today.

\section{Acknowledgements}

We would like to thank the women who made this study possible by bravely sharing their experiences with us. This study was funded by grants from the Swedish Cancer Society, the Cancer Research Funds of Radiumhemmet, the King Gustav V Jubilee Clinic Cancer Foundation, Gothenburg, and the Swedish State under the ALF agreement, Stockholm and Gothenburg.

\section{Conflict of interest statement}

We declare that we have no conflict of interest. The funding sources had no role in study design, data collection, data interpretation, or the writing of this article. The corresponding author had full access to all the data in the study and had final responsibility for the decision to submit for publication.

\section{References}

1. Dunberger, G., et al., Fecal incontinence affecting quality of life and social functioning among long-term gynecological cancer survivors. Int J Gynecol Cancer, 2010. 20(3): p. 449-60.

2. Dunberger, G., et al., Lower limb lymphedema in gynecological cancer survivors-effect on daily life functioning. Support Care Cancer, 2013. 21(11): p. 3063-70.

3. Lefkowits, C., et al., Predictors of high symptom burden in gynecologic oncology outpatients: who should be referred to outpatient palliative care? Gynecol Oncol, 2014. 132(3): p. 698-702.

4. Ferrandina, G., et al., Evaluation of quality of life and emotional distress in endometrial cancer patients: a 2-year prospective, longitudinal study. Gynecol Oncol, 2014. 133(3): p. 518-25.

5. Ye, S., et al., A systematic review of quality of life and sexual function of patients with cervical cancer after treatment. Int J Gynecol Cancer, 2014. 24(7): p. 1146-57.

6. Andersen, B.L. and J. van Der Does, Surviving gynecologic cancer and coping with sexual morbidity: an international problem. Int J Gynecol Cancer, 1994. 4(4): p. 225 240. 
7. Bergmark, K., et al., Vaginal changes and sexuality in women with a history of cervical cancer. N Engl J Med, 1999. 340(18): p. 1383-9.

8. Jensen, P.T., et al., Longitudinal study of sexual function and vaginal changes after radiotherapy for cervical cancer. Int J Radiat Oncol Biol Phys, 2003. 56(4): p. 93749.

9. Jensen, P.T., et al., Early-stage cervical carcinoma, radical hysterectomy, and sexual function. A longitudinal study. Cancer, 2004. 100(1): p. 97-106.

10. Flay, L.D. and J.H. Matthews, The effects of radiotherapy and surgery on the sexual function of women treated for cervical cancer. Int J Radiat Oncol Biol Phys, 1995. 31(2): p. 399-404.

11. Park, S.Y., et al., Quality of life and sexual problems in disease-free survivors of cervical cancer compared with the general population. Cancer, 2007. 110(12): p. 2716-25.

12. Frumovitz, M., et al., Quality of life and sexual functioning in cervical cancer survivors. J Clin Oncol, 2005. 23(30): p. 7428-36.

13. Greimel, E.R., et al., Quality of life and sexual functioning after cervical cancer treatment: a long-term follow-up study. Psychooncology, 2009. 18(5): p. 476-82.

14. Abbott-Anderson, K. and K.L. Kwekkeboom, A systematic review of sexual concerns reported by gynecological cancer survivors. Gynecol Oncol, 2012. 124(3): p. 477-89.

15. Steineck, G., et al., Symptom documentation in cancer survivors as a basis for therapy modifications. Acta Oncol, 2002. 41(3): p. 244-52.

16. Sweden, S., Statistical Yearbook of Sweden. 2013, Stockholm: Statistics Sweden.

17. Steineck, G., H. Hunt, and J. Adolfsson, A hierarchical step-model for causation of bias-evaluating cancer treatment with epidemiological methods. Acta Oncol, 2006. 45(4): p. 421-9.

18. Kreicbergs, U., et al., Talking about death with children who have severe malignant disease. N Engl J Med, 2004. 351(12): p. 1175-86.

19. Bylund Grenklo, T., et al., Self-injury in teenagers who lost a parent to cancer: $a$ nationwide, population-based, long-term follow-up. JAMA Pediatr, 2013. 167(2): p. 133-40.

20. Omerov, P., et al., Preparatory studies to a population-based survey of suicidebereaved parents in Sweden. Crisis, 2013. 34(3): p. 200-10.

21. Lind, H., et al., Late symptoms in long-term gynaecological cancer survivors after radiation therapy: a population-based cohort study. Br J Cancer, 2011. 105(6): p. 737-45.

22. Noronha, A.F., et al., Treatments for invasive carcinoma of the cervix: what are their impacts on the pelvic floor functions? Int Braz J Urol, 2013. 39(1): p. 46-54.

23. Bergmark, K., et al., Lymphedema and bladder-emptying difficulties after radical hysterectomy for early cervical cancer and among population controls. Int J Gynecol Cancer, 2006. 16(3): p. 1130-9.

24. Beesley, V., et al., Lymphedema after gynecological cancer treatment : prevalence, correlates, and supportive care needs. Cancer, 2007. 109(12): p. 2607-14.

25. Clarke, J.N. and M.M. Everest, Cancer in the mass print media: fear, uncertainty and the medical model. Soc Sci Med, 2006. 62(10): p. 2591-600.

26. McCallum, M., et al., Sexual health and gynecological cancer: conceptualizing patient needs and overcoming barriers to seeking and accessing services. $\mathrm{J}$ Psychosom Obstet Gynaecol, 2012. 33(3): p. 135-42.

27. Fernandes, T., L.H. Costa-Paiva, and A.M. Pinto-Neto, Efficacy of vaginally applied estrogen, testosterone, or polyacrylic acid on sexual function in postmenopausal women: a randomized controlled trial. J Sex Med, 2014. 11(5): p. 1262-70. 
28. Schofield, P., et al., A nurse- and peer-led support program to assist women in gynaecological oncology receiving curative radiotherapy, the PeNTAGOn study (peer and nurse support trial to assist women in gynaecological oncology): study protocol for a randomised controlled trial. Trials, 2013. 14: p. 39.

29. Decruze, S.B., D. Guthrie, and R. Magnani, Prevention of vaginal stenosis in patients following vaginal brachytherapy. Clin Oncol (R Coll Radiol), 1999. 11(1): p. 46-8. 


\begin{tabular}{|c|c|c|}
\hline & $\begin{array}{l}\text { Intercourse during } \\
\text { the previous } 6 \\
\text { months }(n=243)\end{array}$ & $\begin{array}{l}\text { No intercourse } \\
\text { during the } \\
\text { previous } 6 \text { months } \\
(n=373)\end{array}$ \\
\hline & Patients (\%) & Patients (\%) \\
\hline \multicolumn{3}{|l|}{ Age at diagnosis } \\
\hline $18-29$ & $6(2)$ & $2(<1)$ \\
\hline $30-39$ & $29(12)$ & $14(4)$ \\
\hline $40-49$ & $44(18)$ & $33(9)$ \\
\hline $50-59$ & $97(40)$ & $113(30)$ \\
\hline $60-69$ & $57(23)$ & $145(39)$ \\
\hline $70-75$ & $10(4)$ & $66(18)$ \\
\hline \multicolumn{3}{|l|}{ Diagnosis } \\
\hline Cervical cancer & $67(28)$ & $76(20)$ \\
\hline Endometrial cancer & $129(53)$ & $237(64)$ \\
\hline Ovarian cancer & $19(8)$ & $26(7)$ \\
\hline Sarcoma uteri & $14(6)$ & $16(4)$ \\
\hline Tubal cancer & $4(2)$ & $8(2)$ \\
\hline Vaginal cancer & $8(3)$ & $6(2)$ \\
\hline Vulvar cancer & $2(1)$ & $4(1)$ \\
\hline Time from treatment to data collection & \multicolumn{2}{|l|}{ Months (years) } \\
\hline Median & $78(7)$ & $95(8)$ \\
\hline Min - max & $30-180(3-15)$ & $30-183(3-15)$ \\
\hline Estrogen treatment at data collection & \multicolumn{2}{|l|}{ Patients (\%) } \\
\hline Systemic & $51(21)$ & $38(10)$ \\
\hline Local & $66(27)$ & $75(20)$ \\
\hline \multicolumn{3}{|l|}{ Marital Status } \\
\hline Married or living with partner & $187(77)$ & $157(42)$ \\
\hline Widow & $8(3)$ & $76(20)$ \\
\hline In a relationship but lives alone & $31(13)$ & $6(2)$ \\
\hline No relationship and lives alone & $15(6)$ & $133(36)$ \\
\hline Not stated & $1(<1)$ & $1(<1)$ \\
\hline \multicolumn{3}{|l|}{ Parity } \\
\hline Nulli para & $49(20)$ & $111(30)$ \\
\hline 1 or 2 para & $128(53)$ & $162(43)$ \\
\hline$\geq 3$ para & $66(27)$ & $99(27)$ \\
\hline Not stated & $0(0)$ & $1(<1)$ \\
\hline \multicolumn{3}{|l|}{ Smoking } \\
\hline Current smoker & $50(21)$ & $92(25)$ \\
\hline Former smoker & $77(32)$ & $105(28)$ \\
\hline Never smoked & $109(46)$ & $168(46)$ \\
\hline Not stated & $2(1)$ & $4(1)$ \\
\hline \multicolumn{3}{|l|}{ Body Mass Index (BMI) } \\
\hline$<18.5$ (lean) & $2(1)$ & $14(4)$ \\
\hline 18.6-24.9 (normal weight) & $112(48)$ & $149(44)$ \\
\hline $25.0-29.9$ (overweight) & $81(35)$ & $120(35)$ \\
\hline$\geq 30$ (obese) & $38(16)$ & $59(17)$ \\
\hline Not stated & $10(4)$ & $31(9)$ \\
\hline
\end{tabular}




\begin{tabular}{|c|c|c|}
\hline Hypertension & $74(30)$ & $153(41)$ \\
\hline Diabetes Mellitus & $14(6)$ & $48(13)$ \\
\hline \multicolumn{3}{|l|}{ Total irradiation } \\
\hline$<35 \mathrm{~Gy}^{\mathrm{a}}$ without $\mathrm{BT}^{\mathrm{b}}$ & $1(2)$ & $3(5)$ \\
\hline $35-40$ Gy without BT & $5(10)$ & $5(8)$ \\
\hline 40-45 Gy without BT & $26(54)$ & $34(52)$ \\
\hline 45-50 Gy without BT & $6(13)$ & $6(9)$ \\
\hline$\geq 50$ Gy without $\mathrm{BT}$ & $10(21)$ & $18(27)$ \\
\hline$\leq 35$ Gy and $\mathrm{BT}$ & $0(0)$ & $3(1)$ \\
\hline $35-40 \mathrm{~Gy}$ and BT & $61(31)$ & $93(30)$ \\
\hline $40-45$ Gy and BT & $29(15)$ & $71(23)$ \\
\hline 45-50 Gy and BT & $89(46)$ & $112(37)$ \\
\hline$\geq 50$ Gy and $\mathrm{BT}$ & $16(8)$ & $27(9)$ \\
\hline \multicolumn{3}{|l|}{ Surgery } \\
\hline $\begin{array}{l}\text { Hysterectomy, } \mathrm{SOE}^{\mathrm{c}} \text {, lymph ovh oment }{ }^{\mathrm{d}} \\
+/ \text { - oophrectomy }\end{array}$ & $216(89)$ & $327(88)$ \\
\hline Vulvar surgery & $3(1)$ & $4(1)$ \\
\hline Other surgery & $4(2)$ & $1(<1)$ \\
\hline No surgery & $20(8)$ & $41(11)$ \\
\hline $\begin{array}{l}\text { Distribution of dyspareunia among } \\
\text { women sexually active }(n=243)^{\mathrm{e}}\end{array}$ & \multicolumn{2}{|l|}{ Patients (\%) } \\
\hline Superficial dyspareunia ${ }^{\mathrm{f}}$ & \multicolumn{2}{|l|}{$134(55)$} \\
\hline Deep dyspareunia ${ }^{\mathrm{g}}$ & \multicolumn{2}{|l|}{$97(40)$} \\
\hline Superficial dyspareunia only & \multicolumn{2}{|l|}{$47(19)$} \\
\hline Deep dyspareunia only & \multicolumn{2}{|l|}{$10(4)$} \\
\hline Both superficial and deep dyspareunia & \multicolumn{2}{|l|}{$87(36)$} \\
\hline No dyspareunia & \multicolumn{2}{|l|}{$82(34)$} \\
\hline Missing & \multicolumn{2}{|l|}{$17(7)$} \\
\hline
\end{tabular}

${ }^{\mathrm{a}} \mathrm{Gy}=$ Grey

${ }^{\mathrm{b}} \mathrm{BT}=$ Brachytherapy

${ }^{\mathrm{c}} \mathrm{SOE}=$ Salpingo-oophorectomy

${ }^{\mathrm{d}}$ Lymph ovh oment $=$ lymph oophorectomy

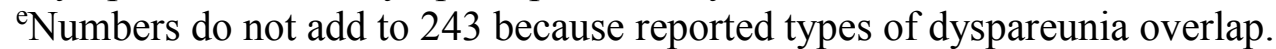

f Includes women reporting superficial dyspareunia only and both types of dyspareunia

${ }^{\mathrm{g}}$ Includes women reporting deep dyspareunia only and both types of dyspareunia 
Table 2.

\begin{tabular}{|c|c|c|c|c|}
\hline \multicolumn{5}{|c|}{$\begin{array}{l}\text { Late symptoms with intercourse during the past six months among gynecological } \\
\text { cancer survivors treated with pelvic radiation therapy with or without surgery } \\
(\mathrm{n}=\mathbf{2 4 3})\end{array}$} \\
\hline & \multicolumn{2}{|c|}{$\begin{array}{l}\text { Women reporting } \\
\text { superficial } \\
\text { dyspareunia } \\
(\mathbf{n}=135) *\end{array}$} & \multicolumn{2}{|c|}{$\begin{array}{l}\text { Women reporting } \\
\text { deep dyspareunia } \\
\qquad(\mathbf{n}=97)^{*}\end{array}$} \\
\hline & $\begin{array}{l}\text { No./Total } \\
(\%)\end{array}$ & $\begin{array}{l}\text { RR }(95 \% \\
\text { CI })\end{array}$ & $\begin{array}{l}\text { No./Total } \\
(\%)\end{array}$ & $\begin{array}{l}\text { RR }(95 \% \\
\text { CI })\end{array}$ \\
\hline \multicolumn{5}{|l|}{ Vaginal elasticity } \\
\hline Moderate/good & $77 / 155(50)$ & 1.0 & $52 / 155(34)$ & 1.0 \\
\hline No/little & $55 / 70(79)$ & $\begin{array}{l}1.58(1.29- \\
1.93)\end{array}$ & $44 / 70(63)$ & $\begin{array}{l}1.87 \\
(1.41- \\
2.49)\end{array}$ \\
\hline $\begin{array}{l}\text { Adjusted for vaginal lubrication } \\
\text { when aroused }\end{array}$ & & $\begin{array}{l}1.24(0.98- \\
1.57)\end{array}$ & & $\begin{array}{l}1.80 \\
(1.33- \\
2.44)\end{array}$ \\
\hline Adjusted for age $<60 * *$ & & Not done & & $\begin{array}{l}1.92 \\
(1.49- \\
2.47)\end{array}$ \\
\hline $\begin{array}{l}\text { Adjusted for age and } \\
\text { lubrication** }\end{array}$ & & Not done & & $\begin{array}{l}1.89 \\
(1.41- \\
2.51)\end{array}$ \\
\hline $\begin{array}{l}\text { Adjusted for vaginal lubrication } \\
\text { and swollen lower abdomen** }\end{array}$ & & $\begin{array}{l}1.24(0.98- \\
1.56)\end{array}$ & & Not done \\
\hline \multicolumn{5}{|l|}{$\begin{array}{l}\text { Vaginal lubrication when sexually } \\
\text { aroused }\end{array}$} \\
\hline Moderate/good & $53 / 119(45)$ & 1.0 & $42 / 119(35)$ & 1.0 \\
\hline No/little & 78/101 (77) & $\begin{array}{l}1.73(1.38- \\
2.18)\end{array}$ & $51 / 100(51)$ & $\begin{array}{l}1.45 \\
(1.06- \\
1.97)\end{array}$ \\
\hline Adjusted for elasticity & & $\begin{array}{l}1.51(1.15- \\
1.98)\end{array}$ & & $\begin{array}{l}1.11 \\
(0.83- \\
1.47) \\
\end{array}$ \\
\hline $\begin{array}{l}\text { Adjusted for swollen lower } \\
\text { abdomen** }\end{array}$ & & $\begin{array}{l}1.67(1.32- \\
2.11)\end{array}$ & & Not done \\
\hline $\begin{array}{l}\text { Adjusted for swollen lower } \\
\text { abdomen and elasticity** }\end{array}$ & & $\begin{array}{l}1.51(1.15- \\
1.98)\end{array}$ & & Not done \\
\hline \multicolumn{5}{|l|}{$\begin{array}{l}\text { Genital engorgement when } \\
\text { sexually aroused }\end{array}$} \\
\hline $\begin{array}{l}\text { More than half the time/Every } \\
\text { time }\end{array}$ & $67 / 112(60)$ & 1.0 & $49 / 113(43)$ & 1.0 \\
\hline Never/Less than half the time & $60 / 100(60)$ & $\begin{array}{l}1.00(0.80- \\
1.25)\end{array}$ & $42 / 98(43)$ & $\begin{array}{l}0.99 \\
(0.72- \\
1.35)\end{array}$ \\
\hline Adjusted for lubrication** & & $\begin{array}{l}0.87(0.73- \\
1.04)\end{array}$ & & Not done \\
\hline
\end{tabular}




\begin{tabular}{|c|l|l|l|l|}
\hline Adjusted for elasticity** & & Not done & & $\begin{array}{l}0.88 \\
(0.66- \\
1.16)\end{array}$ \\
\hline Age at follow-up & & & & \\
\hline$>/=60$ & & & $44 / 138(32)$ & 1.0 \\
\hline$<60$ & & & $53 / 90(59)$ & $\begin{array}{l}1.85 \\
(1.37- \\
\end{array}$ \\
\hline Adjusted for elasticity** & & & & $2.49)$ \\
\hline $\begin{array}{c}\text { Adjusted for lubrication and } \\
\text { elasticity** }\end{array}$ & & Not done & & $\begin{array}{l}1.85 \\
(1.41- \\
\end{array}$ \\
\hline Swollen lower abdomen & & Not done & & $\begin{array}{l}1.75 \\
(1.33- \\
2.30)\end{array}$ \\
\hline No & & & & \\
\hline Yes & $93 / 176(53)$ & & & \\
\hline
\end{tabular}

*Women reporting having pain to the questions regarding superficial and deep pain, respectively.

**Statistical adjustment limited to known confounders. 


\section{Figure 1. Flow chart for study population}

1800 Identified gynaecological cancer patients treated with external pelvic radiotherapy, between the years 1991 and 2003 at Karolinska University Hospital, Stockholm or Sahlgrenska University Hospital, Gothenburg

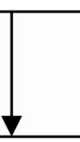

977 Did not meet eligibility criteria:

Dead at follow-up, born before 1927, could not understand/read Swedish, had recurrent cancer, had not received pelvic radiation

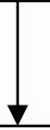

An introductory letter was sent to 823 eligible survivors

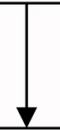

126 non-participants. Reasons for not participating in the study:

Refused to participate without reason, physical reasons, not reachable

697 (85\%) survivors gave informed oral consent and were sent a questionnaire

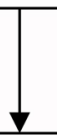

81 survivors did not complete the study: Agreed but did not return the questionnaire or returned an empty questionnaire

650 survivors returned a questionnaire and participated in the project

34 survivors excluded from present analysis due to recurrent cancer

616 survivors $(78 \%)$ included in analysis

Sub analyses conducted on the 243 survivors who reported having engaged in intercourse during the previous 6 months 